\title{
ASPECTOS PSICOLÓGICOS EN LA INVESTIGACIÓN CIENTÍFICA
}

\author{
Luis Alberto Rodríguez de los Ríos ${ }^{26}$
}

\section{INTRODUCCIÓN}

Los estudios de posgrado se caracterizan, fundamentalmente, por instrumentalizar en sus usuarios los aspectos teóricos, lógicos, metodológicos y formales de la investigación científica con propósitos de lograr cierto nivel de experticia que les permita la producción y difusión de conocimientos disciplinares novedosos y críticos que impliquen un aporte significativo tanto a nivel teórico-conceptual como praxeológico.

Una de las competencias a desarrollar en este contexto está referida a la concepción y elaboración de un proyecto de investigación, la misma que se logra mediante la aprobación de asignaturas como: epistemología, metodología de la investigación y talleres de elaboración de proyectos de investigación, bajo las modalidades de enseñanza racional - cognitiva - experiencial (aprender-aprendiendo) bajo la tutela de investigadores expertos. Sin embargo, dicha competencia no siempre se logra satisfactoriamente, pues, el porcentaje de estudiantes que presentan su proyecto de investigación al término de sus estudios es muy bajo. Algunos estudios estiman por debajo del $5 \%$ a nivel nacional. (Rodríguez de los Ríos, 2002).

Se han identificado múltiples factores para explicar la baja eficacia terminal de los estudios de posgrado. Refiriéndose, la mayoría de ellos, a aspectos didácticos, metodológicos, económicos, administrativos y académicos; obviando, el factor psicológico, donde el protagonista de todo el proceso de investigación es el estudiante investigador. Quien es una persona con una estructura psíquica integrada por necesidades, objetivos, motivaciones, actitudes, intereses, valores emocionales, sentimientos, constancia y creatividad.

Lo anterior lo podemos evidenciar en la mayoría de los manuales de metodología de la investigación donde se identifican el "proceso de la investigación" con un esquema rígido de pasos que se deberían seguir para investigar; ignorando al investigador y su mundo psicológico. De este mundo psicológico surgen justamente los elementos más creativos, el interés hacia el tema, la motivación hacia la investigación, las necesidades y conflictos, la constancia y la persistencia, en otras palabras, el factor humano, sin el cual carece de sentido cualquier investigación aunque sea metodológicamente pura.

\section{FACTORES PSICOLÓGICOS EN EL PROCESO DE LA INVESTIGACIÓN CIENTÍFICA}

Como ya se indicó en el apartado anterior los textos o manuales sobre metodología de investigación describen con detalle el "qué" y el "cómo" de la investigación, dejando afuera "quién" lo hace, "quién" vive ese proceso y produce la investigación, qué sucede en la persona que investiga, cuáles son sus dificultades, intereses, características, emociones, valores y actitudes y cómo se reflejan en la investigación.

A continuación siguiendo a Casado (2001) describiremos los factores psicológicos presentes en el proceso de la investigación, a saber:

Creatividad: no sólo para seleccionar y formular los problemas de investigación, sino realizar todas las otras fases de la investigación. Es la

\footnotetext{
${ }^{26}$ rodri0351@hotmail.com
} 
función creativa del investigador y se le conoce también como pensamiento divergente, espíritu libre, mentalidad abierta y libertad creadora.

Actividad teórica, epistemológica 0 de pensamiento, que el investigador desarrolla para buscar explicaciones 0 atribuir sentido a los hechos. En ella influyen sus antecedentes socioculturales pero también su propia historia, personalidad y experiencia.

Estilo en la comunicación escrita de los resultados de la investigación es la función de escritor del investigador .El estilo tiene estrecha vinculación con la personalidad, refleja además la historia, valores e inconsciente (los "fantasmas" de Sábato o "demonios" de Vargas Llosa) del investigador.

Motivación, objetivos, intereses, habilidades, experiencia y conocimientos, los cuales impulsan, dirigen, desarrollan y mantienen la investigación en la práctica diaria y ayudan a sobrellevar las dificultades del quehacer, del oficio del investigador.

Antidogmatismo y espíritu crítico: aunque apunta más a lo racional, cognitivo, son complemento indispensable de la creatividad 0 libertad creadora.

Angustia y conflicto acompañan al investigador, especialmente al novato, en varias fases de la investigación, pero son notorias al comienzo cuando se están escogiendo temas y problemas de investigación y al final cuando se está escribiendo el informe para divulgar los resultados con claridad, precisión y economía .Pero en todo el proceso de la pesquisa, la angustia y el conflicto están presentes en el quehacer del investigador.

Paciencia, tolerancia a la frustración y a la ambigüedad .La primera se requiere para ir seleccionando, leyendo y acumulando información sobre el tema, organizarlo y finalmente redactarlo en forma coherente. La segunda para enfrentar las limitaciones y modificaciones que necesariamente experimenta un trabajo de investigación, desde su concepción, hasta su presentación final. Pero también se necesita tolerar e interpretar resultados adversos o inesperados y enfrentar las opiniones contrarias a nuestra hipótesis y hallazgos.

Las manifestaciones psicológicas del estrés se presentan también como inevitables acompañantes en un proceso exigente en lo físico e intelectual, que dura generalmente, varios meses 0 años y cuya conclusión es una meta de vital importancia para el investigador, ya que será juzgado y valorado por el producto escrito de su trabajo. Manifestaciones frecuentes del estrés en los tesistas de pregrado son: insomnio, irritabilidad, depresión reactiva, sentimiento de minusvalía, agotamiento y confusión mental, propensión al abandono 0 a la interrupción del trabajo, posición del trabajo, dispersión angustiosa en actividades secundarias 0 no relacionadas con sus objetos, las cuales consumen tiempo y se constituyen en justificación para no concluir a tiempo, entre otras.

Sentimientos de soledad y aislamiento intelectual ocupan por sí solo una categoría, a juzgar por los hallazgos de varios investigadores que han estudiado el asunto en relación con los estudiantes de posgrado.

El equilibrio emocional, junto con la paciencia y la tolerancia a la frustración, ya citados, permiten al investigador mantenerse lo menos afectado posible por las contingencias ambientales. En lo personal debe aprovechar su emoción estética y el interés de la búsqueda intelectual, como motivadores poderosos para el trabajo en circunstancias adversas, y controlar las emociones negativas de depresión, abandono y negatividad.

Constancia y continuidad en el trabajo son rasgos de suma importancia para el investigador. Probablemente - y más que las destrezas metodológicas-determinan el éxito o el fracaso en una investigación. 
Capacidad de observación y atención.

Los procesos psicológicos de percepción, memoria y razonamiento constituyen los instrumentos de que dispone el investigador para obtener conocimiento acerca de los hechos de la realidad objetiva.

\section{REFERENCIA BIBLIOGRÁFICA}

Casado, E. Hacia una psicología de la investigación. Caracas. Universidad Central de Venezuela. 2004

García, M. y Marlott, R.W. Una solución al fenómeno todo menos tesis y disertación. En Revista Intercontinental de Psicología y Educación. Vol. 1, No 2: pp. 205 - 216. 1988.

Rodríguez de los Ríos, L. La tutoría académica: Una alternativa para viabilizar la graduación en las Escuelas de Postgrado. En revista academia. Escuela de Postgrado. Universidad Inca Garcilaso de la Vega, pp. 127 - 137, 2002.

\section{INSTRUCCIONES A LOS AUTORES PARA LA EDICIÓN DE ARTÍCULO CIENTÍFICO}

La revista "Prospectiva Universitaria" es una revista científica publicado por el Centro de Investigación de la Universidad Nacional del Centro del Perú; integra las investigaciones en varias áreas de la ciencia, desarrollados por investigadores de la UNCP. Las contribuciones científicas pueden ser enviadas impreso y digital a la Oficina General de Investigación y a los correos: investigación@uncp. edu.pe, prospectivauniversitaria@gmail.com; en las siguientes formas:

Artículos 0 notas científicas sobre temas relacionados con el conocimiento científico.

Revisiones de literatura, realizado por profesionales de reconocida competencia en el tema presentado.
Cartas al editor, un máximo de 4 páginas dactilografiadas, conteniendo uno de los siguientes temas: a) comunicaciones de materia directamente ligadas al conocimiento científico. b) Comentarios críticos de trabajos publicados en la revista "Prospectiva universitaria" o en otra de naturaleza científica.

Serán aceptados trabajos de investigación escritos en el idioma español o inglés. Después de ser revisados y aprobados por el Comité editorial, entendiéndose que no han sido publicados ni estuvieran en la condición de ser sometidos para su publicación en otra revista. Se exceptúan aquellos trabajos que fueron presentados en Congresos, únicamente en la forma de resumen.

Los artículos cientíicos, deberán ser divididos en secciones con encabezamiento en el siguiente orden: TíTULO, RESUMEN, ABSTRAC, INTRODUCCIÓN, MATERIALES Y MÉTODOS, RESULTADOS, DISCUSIÓN, CONCLUSIONES, AGRADECIMIENTOS $Y$ LITERATURA CITADA.

El documento deberá estar en letra número 9, tipo de letra Arial con los márgenes del documento son de $1,5 \mathrm{~cm}$ a cada lado; siendo el tamaño $17 \mathrm{~cm} \times 23.5 \mathrm{~cm}$.

Los investigadores que han participado directamente en el desarrollo del trabajo de investigación son considerados debajo del título. El autor correspondiente del trabajo debe quedar señalizado con un asterisco.

Al lado izquierdo del pie página (ver ejemplo), se indicará:

Departamento académico, Programa de investigación, Universidad al que pertenecen los participantes en la investigación.

Fecha de recepción del artículo científico por el comité editorial.

En asterisco señalar el autor correspondiente, 
indicar su e-mail.

Estas secciones deben estar compuestas de la siguiente forma:

TÍTULO del artículo, debe ser conciso, preciso e debe indicar el contenido del trabajo. No más de 20 palabras.

RESUMEN, debe ser presentado de manera directa lo que fue realizado y estudiado, indicando los aspectos metodológicos importantes, se enfatiza los resultados y conclusiones más relevantes. No debe sobrepasar 250 palabras.

ABSTRACT es la traducción fiel del resumen al inglés.

Palabras clave (Key Words), usar palabras que indiquen temas importantes del trabajo. Tras el resumen los autores deberán presentar e identificar como tales, de 3 a 10 palabras que faciliten a los documentalistas el análisis documental del artículo.

INTRODUCCIÓN, debe ser breve, esclareciendo la naturaleza del problema de investigación estudiado. Insertar el problema en un sustento teórico; podría considerarse la (s) hipótesis del trabajo, con citación bibliográfica específica (entre paréntesis y en orden numérico de las citas); finalizar indicando los objetivos de la investigación.

MATERIALES $\mathbf{Y}$ MÉTODOS, deben ser compilados los datos que permitan la repetición del trabajo por otros investigadores. Considerar: lugar de ejecución del trabajo, procedencia del material usado. Población y muestra. Precisar las metodologías de análisis. Diseño experimental, factores y niveles en estudio, tratamientos, procedimientos y pruebas estadísticas realizadas en la contrastación de la hipótesis. Utilizar el sistema internacional de unidades (un máximo de 1,5 páginas) (los ítems a ser considerados en ésta debe ajustarse a la naturaleza de la investigación).

RESULTADOS, deben contener una información precisa de los datos obtenidos. Los cuadros, diagramas, gráficos son auto explicativos, éstos llevan referencia en el texto, numerados en arábigos en orden correlativo de cada uno.

DISCUSION, los resultados deben ser analizados tomando en consideración referencias bibliográficas, la inferencia de los resultados es una característica. Un aspecto medular de esta parte es llevar la información refinada a un nivel de análisis de la información. El análisis crítico debe ser direccionado por la hipótesis del trabajo de investigación. Se debe estimular a la especulación o conjetura basado en los datos obtenidos, basada firmemente en sustentos teóricos del conocimiento científico. Si el fenómeno en estudio es complejo y extenso se recomienda desglosar en secciones colocando subtítulos.

AGRADECIMIENTOS, es opcional, deben ser sucintos, no deben aparecer en el texto ni en pie de página.

REFERENCIA BIBLIOGRÁFICA, debe tener las siguientes características, según corresponda la cita bibliográfica.

Las citaciones en el texto, incluyen el apellido paterno seguido de iniciales del materno y primer nombre (ejemplo: Mable P.R., 2006). Sin son dos autores citarlos a los dos (Mable P.R. y Patry O.C., 2004). Con citaciones de documentos de cuatro a mas autores (Deeks et al., 2005). 